NOT FOR QUOTATION

WITHOUI THE PERMISSION OF THE AUTHOR

\title{
RENEWABLE FNERGIES IN A HISTORICAL CONTEXT
}

Cesare Marchetti

December 1985

PP-85-2

Keynote address, INTERSOL'85, World Solar Energy Conference, Montreal, June 1985.

Professional Papers do not report on work of the International Institute for Applied Systems Analysis, but are produced and distributed by the Institute as an aid to staff members in furthering their professional activities. Views or opinions expressed are those of the author(s) and should not be interpreted as representing the view of either the Institute or its National Member Organizations.

INTERNATIONAL INSTITUTE FOR APPLIED SYSTEMS ANALYSIS

2361 Laxenburg. Austria 



\section{Resume}

The question of renewable energy is first re-defined in the appropriate physical context.

The question of primary energies use and substitution is re-deflned in the appropriate socio-economic (cultural) context.

The conclusion is that for the next future ( 50 years), the most likely use of renewable energies is in special niches, where they can provide unique services and are not in an all-out conquest of the global energy market. 



\title{
RENEWABLE ENERGIES IN A HISTORICAL CONTEXT
}

\author{
Cesare Marchetti
}

The image of the universe in modern cosmologies is extremely dynamic. A quintessential flux as expressed by Heraclit, almost three thousand years ago. But the flux has now precise qualifiers: what flows is free energy, or negentropy, continuously destroyed. It is the destruction that keeps the universe going in a hierarchy of big wheel, small gear and tiny cogs, and all subsystems in a sense compete for it.

In this vision nothing is really renewable, but many things can be considered that way if taken out of context. The crops that grow every year are renewable, as is the flow of light from the sun, although the sun itself is not. But the cycle of the crop is short in relation to our lifespan and that of the sun very long, so long in fact that it makes no difference if we consider it as eternal. We can in fact also forget the rest of the universe as the sun, our prime mover, is so dominant. Out of the radiation it pours into the black universe, the earth in fact intercepts something of the order of $2 \cdot 10^{5} \mathrm{TW}$.

This is almost pure free energy, but it is not put to good use. Most of it "crashes" into the $300^{\circ} \mathrm{K}$ of the earth surface. A few percent are channeled into the working of the atmospheric engine. About three billion years ago, some very clever living organisms, already hustling and bustling in the primeval soup, found a way to divert some of the flux into their chemistry, by inventing a complex gadgetry to split water, and using the hydrogen as a powerful reductant. (Three billion years later, solar buffs are trying to do exactly the same.)

The gadgets were stupendous, and in a way or another we all hang from them, although in relative terms the fraction of solar flux channeled into the biological machinery is quite modest: less than one per thousand. Still large however in terms of human activity. In spite of all our agitation and waste we consume, food included; something around $10 \mathrm{TW}$. Norld forests alone have a metabolism of about $100 \mathrm{TW}$. All in all, we are still at the hierarchical level of tiny cogs. Obviously on earth. 
When man started acguiring his identity as a "talking monkey" about three million years ago, his way of life did not differ much from that of any other animal. He was scratching a life by grabbing fruits, seeds, and occasional little animals for the days to commemorate. The basic tenet being the Darwinian and biblical maximization of numbers. In modern terminology, to fill the niche. But the size of the niche depends on technology. The first breakthrough in that sense was the control of fire, acquired apparently about half a million years ago. It was quintessential because 1t could transform stuff inedible to man and other animals into digestible calories, via appropriate heat treatment that weakened barriers and destroyed chemical defenses.

The second step was that of ecological interference and control, by favoring and selecting plants capable of producing large amounts of edible or transformable materials. During all this time something remained constant. The "energy ratio", i.e. the ratio between the "edible" energy extracted from agricultural practice, and that put into them in form of direct and indirect labor. This ratio always stayed between 40 and 50 , and still has this value in extremely sophisticated but unmechanized agriculture like the chinese one.

Why ten thousand years of progress in agricultural practice were not put to work in order to reduce human toil? The answer is that they were all put to work to increase yield per unit surface, and that means again maximizing number. And not by a factor of two. A hunter-gatherer needs about ten square kilometers to survive, and a Chinese peasant about hundred square meters. The ratio is five orders of magnitude.

The densification of human population permitted the ten to twenty percent of "overhead" artisans, priests, medicine men, merchants and bosses to coagulate into cities, the cradle of all our civilization. Population density is actually the most important single factor in determining societal complexity and technological evolution. I have in fact numerous arguments to support the thesis that an essential component of the industrial revolution was the densification of populations in Europe, due to the breakthroughs in agricultural practices during the late renaissance period, and the use of a "three gears" working animal, the horse, which greatly improved transportation, so favoring conurbations. High population density and the progressive, if slow, increase in energy consumption per capita, brought a great increase in spacial density of energy consumption. This was the essential component in the energy revolution.

Each source of energy is in fact a cluster of technologies with certain economies of scale. If energy consumption per unit area increases, the primary energies with higher economies of scale will gain an advantage. Chopping trees and carting them to town has little economies of scale. Opening a coal pit, a lot. So coal got it over wood. Speaking of depletion may have a sense locally. Forests still shed ten times what we want. The only point is that the interfacing technologies do not work properly. As the case of oil shows, with appropriate interfaces we can take it out of the Northern slope.

The final configuration with very dense spacial consumption level are the grids: gas and electricity. The implosion of 
humanity into the cities leads us just to that.

Starting basically with the 19 th century many things become the object of regular statistics, and the analysis can become quantitative. I will do it using a formally simple tool. The concept that evolution consists in a sequence of technological substitutions, regulated by the Volterra-Lotka equations of competition (Table 1). They were originally developed to describe the competition between living species in a given environment, embodying in a quantitative way the concepts of Darwinism. They appear to be an extremely efficient descriptor of social and economic affairs. In other words, the dynamic of a system can be described by decomposing it in competing subsystems quantitatively described by the equations.

As we are interested in the history of renewable energies, we can start from the case of shipping where sails were substituted by engines. (Fig.1). The euqations which are basically one parameter as the second one is only a time cursor, fit remarkably well the actual phenomenon in spite of the very long substitution time. In the same way we can look at the substitution of horses by automobiles, a process that occurred about a century later in the US (Fig.2).

By putting all renewables in a basket, and fossils in another, we can draw the chart of Fig. 3, which shows the complete pattern of penetration for the fossils in the US market. These charts show shares, normalized on the market always taken as unity. Because the size of the market keeps changing it is a moving renormalization value. But obviously things are perceived in relative terms. This methodology has broad applications. We can for instance look at the substitution of various technologies for making steel (Fig.4). After all, primary energies can be seen as clusters of technologies as is the term renewable when we pack a lot of disparate objects into the same container word.

To the basic question of where renewables will go. I can give a system answer, but taking a long detour in order to identify and quantify the rules of the game. The starting point is that new primary energy is a new technology and consequently we should look for the rules in the area of inventions and innovations. That $I$ did in order to solve my problem of forecasting when a new primary energy will be introduced in the substitution game in Fig.5. The data on basic inventions and innovatios I got from a book by Prof. Gerard Mensch, Das Technologische Patt, where they are listed in homogenous chronologies. The invention date is when the first contrievance worked, and the innovation date is when it first sold. Mensch discovered that the process is pulsed in time, and could make nice lumps of inventions and innovations.

I made the slightly daring but a posteriori very successful hypothesis that after all these innovations could be treated as products produced for a certain market: the demand for innovations. As a consequence, the same mathematics should be valid. As we can see in Fig. 6, the bunches of innovations can be ordered into neat lines. Here the "market" is taken as the total number of innovations in a given bunch. Using the biological analogy it is the size of the niche, measured by the 
maximum number of rabbits it can contain. Because the primary energies in Fig. 5 have the same coordinates they can be superposed, and what we see is a fairly good coincidence between the starts of a new wave of innovations and the introduction of a new primary energy.

I must say that the analysis of all the invention-innovation process done in much more detail shows regularities that permit calculating the following wave, the one into which we are living: For the innovations it is the line No.8 of Fig.6. It has no experimental points, as that can be done only a posteriori. But it has nuclear energy starting in pole position. This means that this run is taken already. The next one will start in year 2025, more or less. Certainly many of you will shudder at my confidence on such kind of predictions. The point is that the algorithm I briefly sketched operated like an iron cage for the invention-innovation process during the last two centuries, which is a good omen for its forecasting potential.

There are some caveats to be kept in view when reading these charts. First that only success is analyzed. But if few are chosen, many are called, and the fight in the "snake pit" below the one percent of the market where the charts start can be ferocious. But it can also contain cozy niches. On the other hand, one percent of a large number can be a large number. With total world energy consumption Funning in the range of ten Terawatt, one percent is one hundred Gigawatt.

These observations contain the constructive system's message for the people working in the area of renewable energies. According to the rules it is better not to try to conquer the world. Better consolidating and maturing in the "cozy niches", where business can be done by exploiting the special characteristics of these energies, and the special environments where these characteristics make them superior. After all, electrical batteries never competed head on against electric power stations, but represent a very flourishing business. They may be just waiting for their Edison to make them win against the stations, in form of fuel cells.

My personal message is that victory will not come out of magic. The resources of the competitors will not dry out in an appropriately short period of time. Natural gas appears as the dominant primary energy for the next fifty years and nuclear energy has already a foot in the door. The infrastructures they are developing in order to expand their market may well be a bonus for the following third one, if its technologies are developed appropriately. Hydrogen can match many constraints. victory may well come but through evolutionary paths tightly adhering to boundary conditions. 


\section{REFERENCES}

The arguments in this paper were developed in detail in the following publications:

c. Marchetti. Society as a Learning System: Discovery, Invention and Innovation Cycles Revisited. RR-81-29. International Institute for Applied Systems Analysis, Laxenburg, Austria; and in Technological Forecasting and Social Change, Vol.18 (1980).

c. Marchetti. The Automobile in a system Context. The Past 80 Years and the Next 20 Years. RR-83-18. International Institute for Applied Systems Analysis, Laxenburg, Austria; and in Technological Forecasting and Social. Change, Vol.23 (1983).

C. Marchetti. The Dynamics of Energy Systems and the Logistic Substitution Model. RR-79-13. International Institute for Applied Systems Analysis, Laxenburg, Austria, December 1979.

N. Nakicenovic. The Automotive Road to Technological Change: Diffusion of the Automobile as a Process of Technological Substitution. WP-85-19. International Institute for Applied Systems Analysis, Laxenburg, Austria, April 1985. 
VOLTERRA EQUATIONS OF COMPETITION

$$
\begin{array}{ll}
d N_{1} / d t=\alpha_{1} N_{1}-\lambda_{1} N_{1} N_{2} & \text { small fishes } \\
d N_{2} / d t=a_{2} N_{2}+\lambda_{2} N_{1} N_{2} & \text { large fishes }
\end{array}
$$

AND A MARKET SHARE SOLUTION

Two Competitors

(market $=1)$

F, market fraction of competitor 1

1-F, market fraction of competitor 2

$\log \frac{F_{1}}{1-F_{1}}=a t+b$

where $a$ and $b$ are empirical constants and $t$ is $t$ ime.
Many Competitors

(market $=1)$

n-1 competitors are in the growing or declining phase

$\log \frac{F_{1}}{1-F_{1}}=a_{1} t+b_{1}$

One of the competitors is in transition. It is the oldest of the growing ones and it is defined as $F_{j}=1-\sum_{i \neq j}^{n} F_{1}$.

1.e., as a residual. 


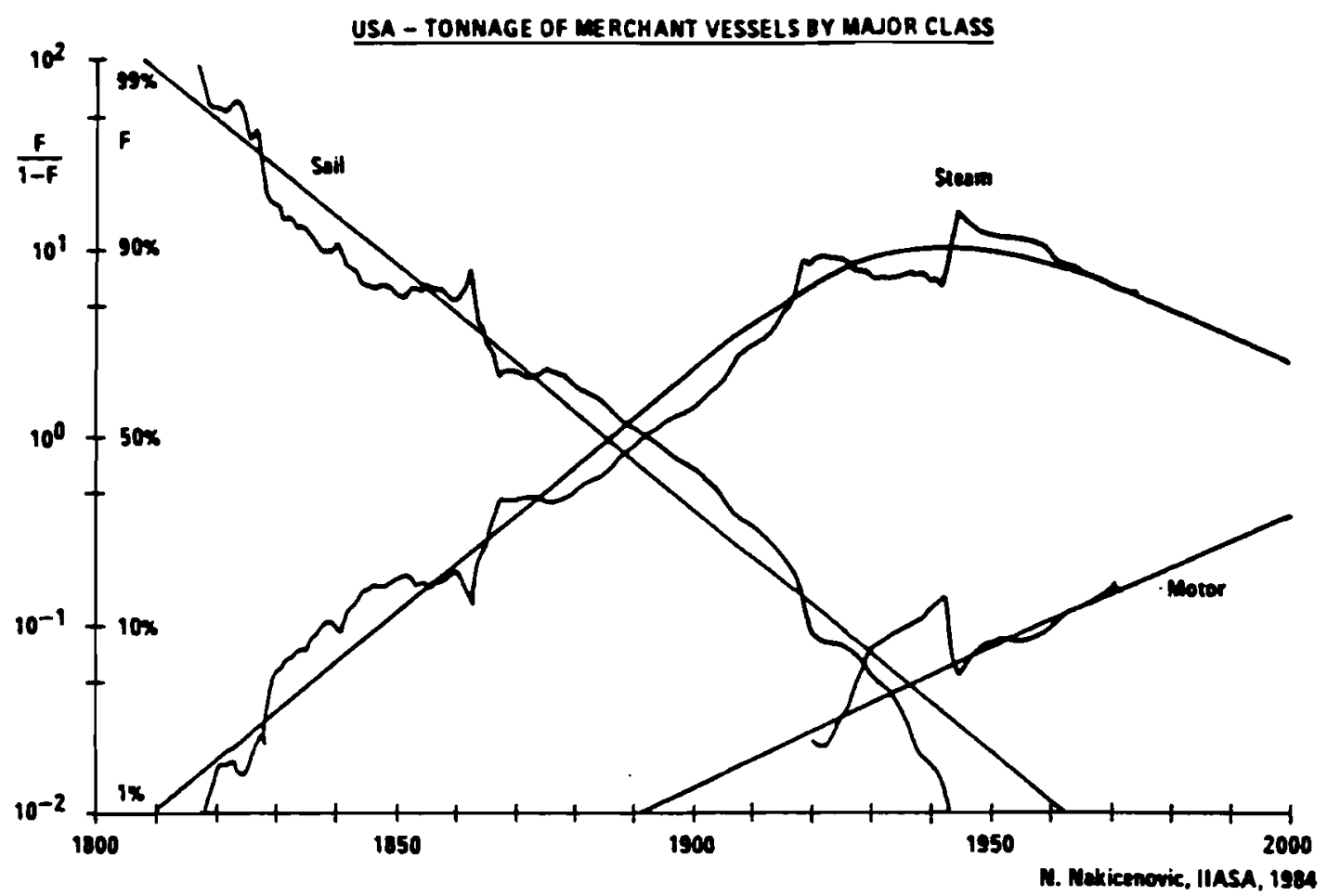

Fig.1. The competition between various propulsion systems for ships is here analyzed using the formalism indicated in the Table. The shares are relative to total tonnage of merchant vessels in US.

USA - SUSTITUTIOM OF MORSES UY AUTOMOALLES

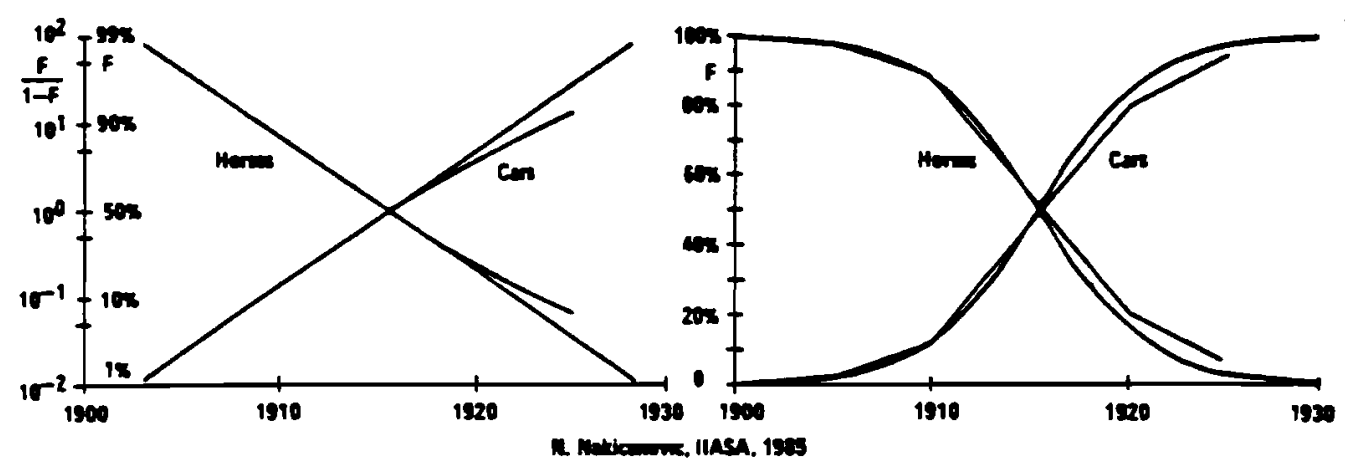

Fig.2. Competition between horses and cars, each counted as a unit. The analysis is here shown using $\log F / 1-F$ and $F$ ordinates to give a better physical appreciation. Statistical data degrade in quality after 1910, perhaps revealing a loss of general interest in horses and the equations are fitted to the first part of the data. 


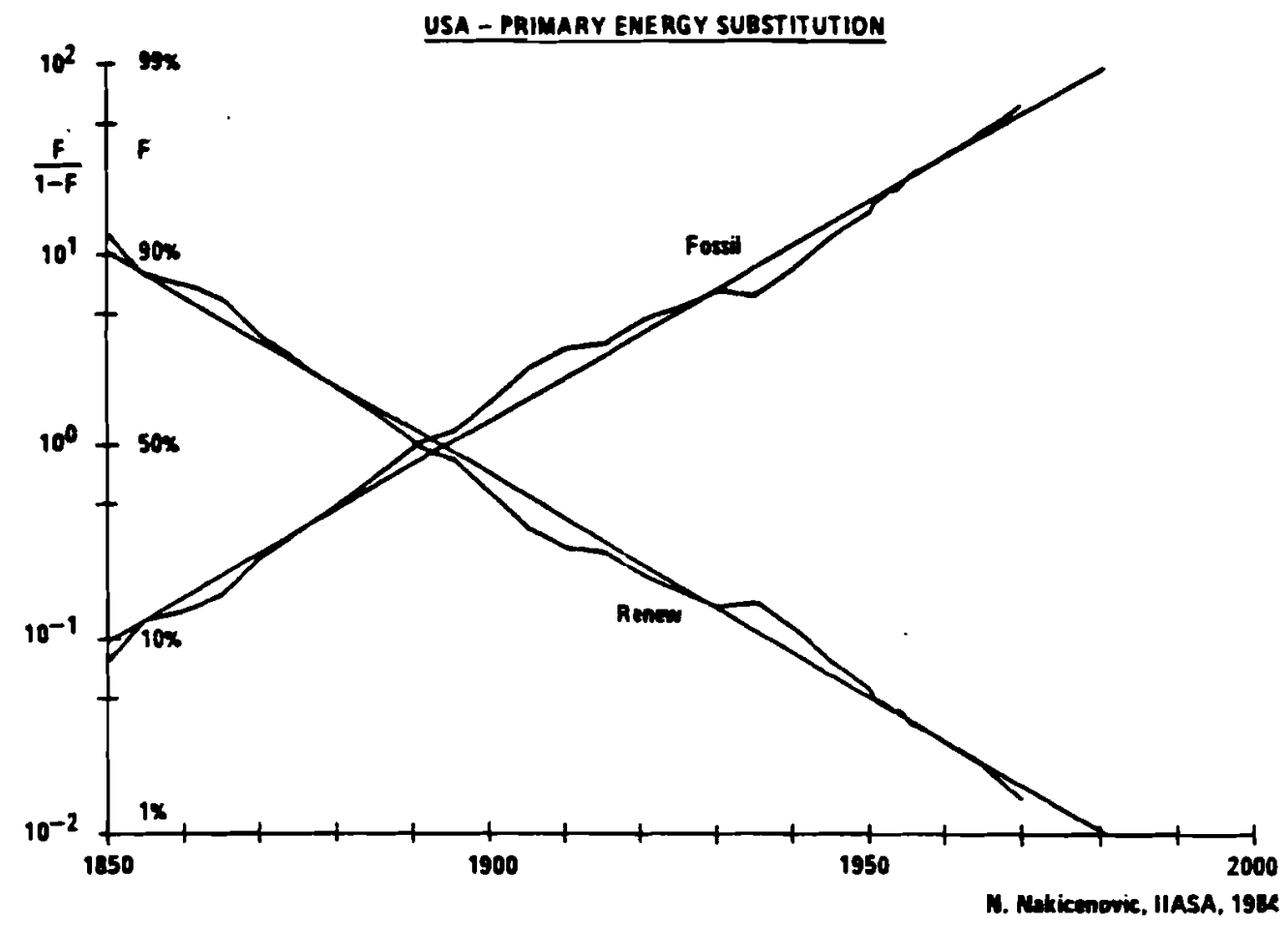

Fig.3. Lumping together all primary inputs into fossils and renewables, $i . e$. new and old, we can analyze with remarkable precision the transition orocess in US. The time constant of this transition (from $90 \%$ to $10 \%$ ) is about 80 years.

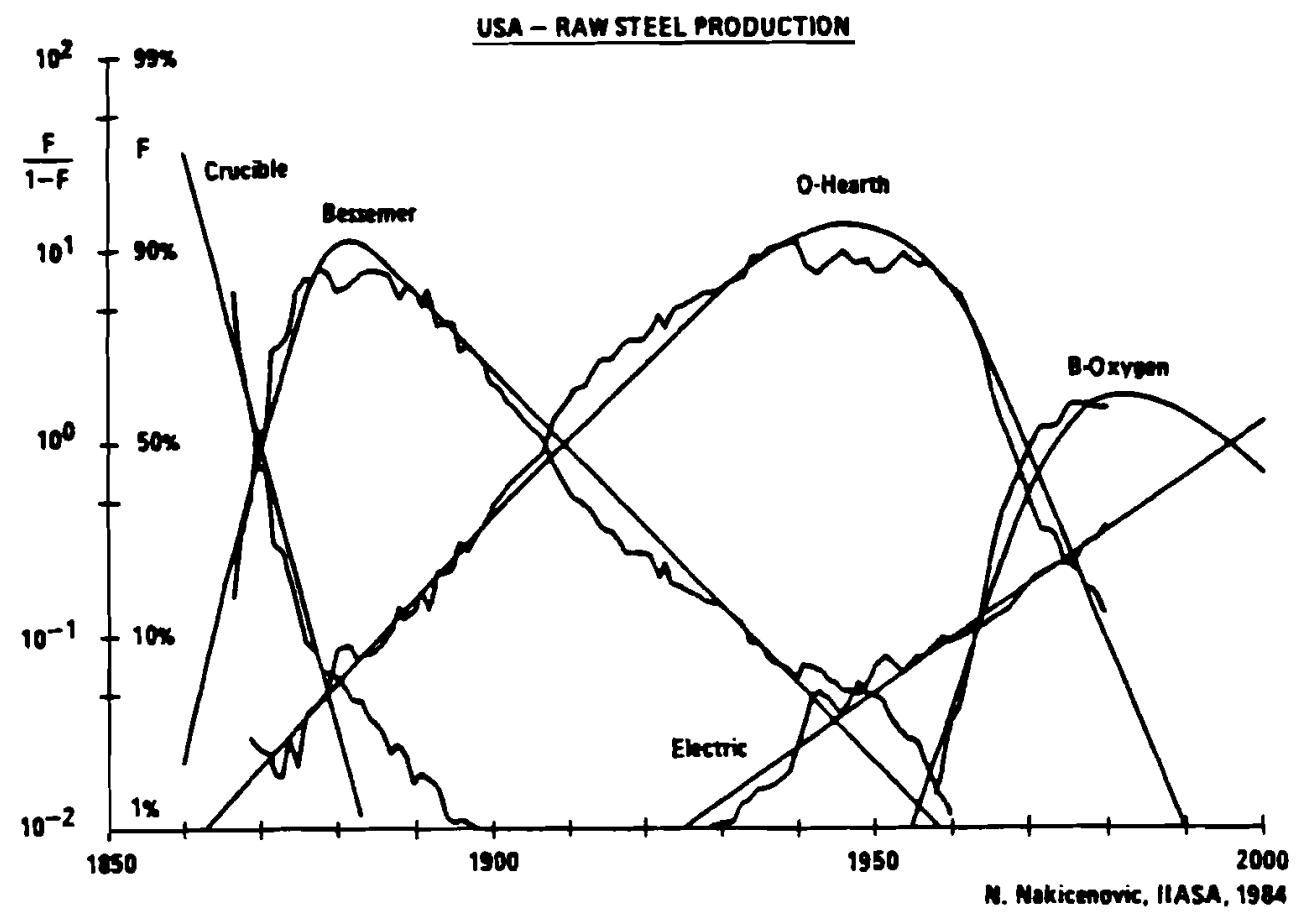

Fig.4. We can look at primary energies as packages of subtechnologies and consequently reduce their behavior to that of technologies. To show that Volterra equations fit the general case, the competition between techniques to make steel is here reported for US. The fit between equations and statistical data is remarkable if we consider the complexity of the steel industry in US and the span of time. 


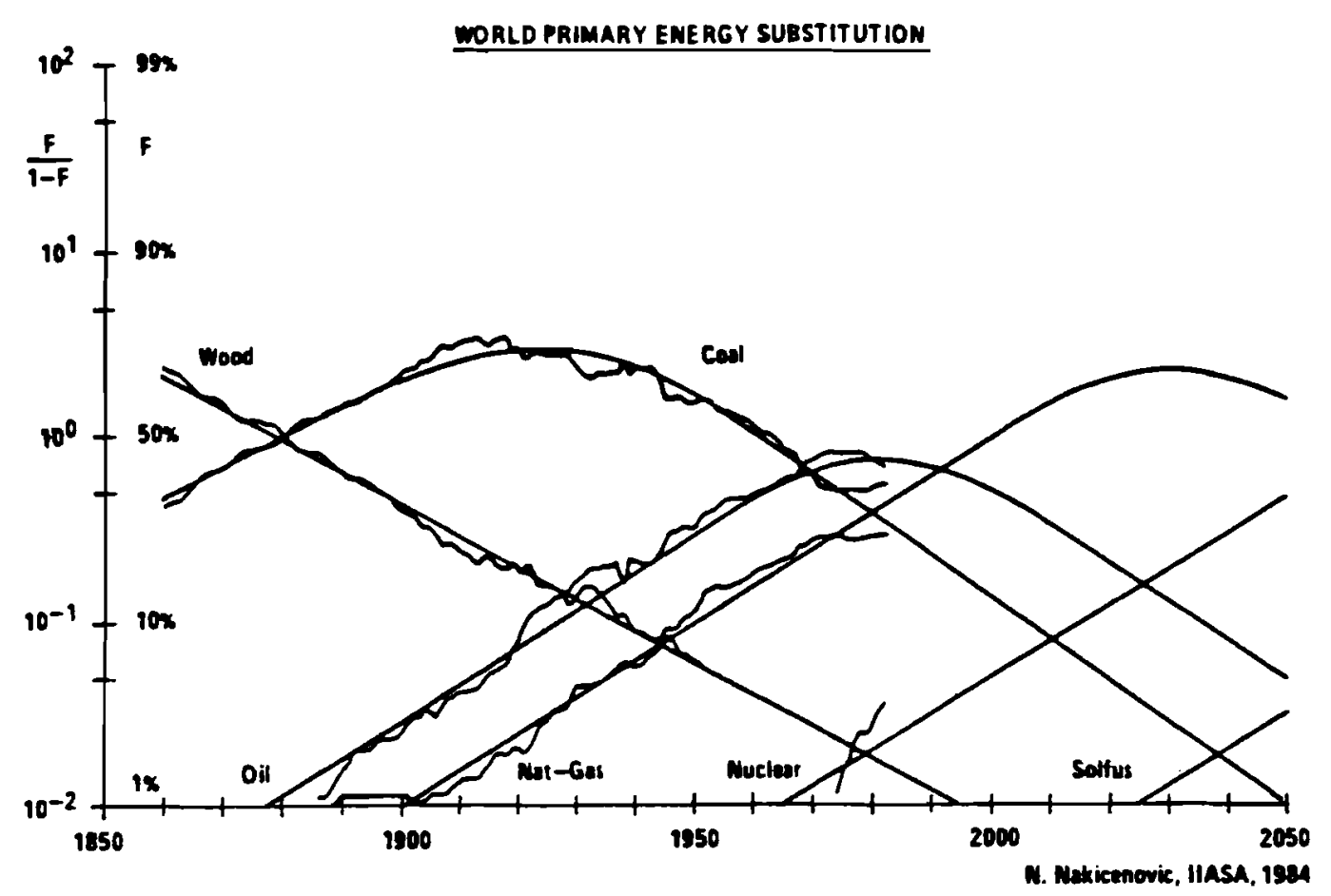

Fig.5. Like technologies primary energies compete. The fast initial penetration rate of nuclear energy is most probably due to the fact it uses a large preexisting grid to sell its product. The Volterra model forecasts a brililant future to natural gas.

\section{INNOVATION WAVES AND THE START OF NEW ENERGY SOURCES}

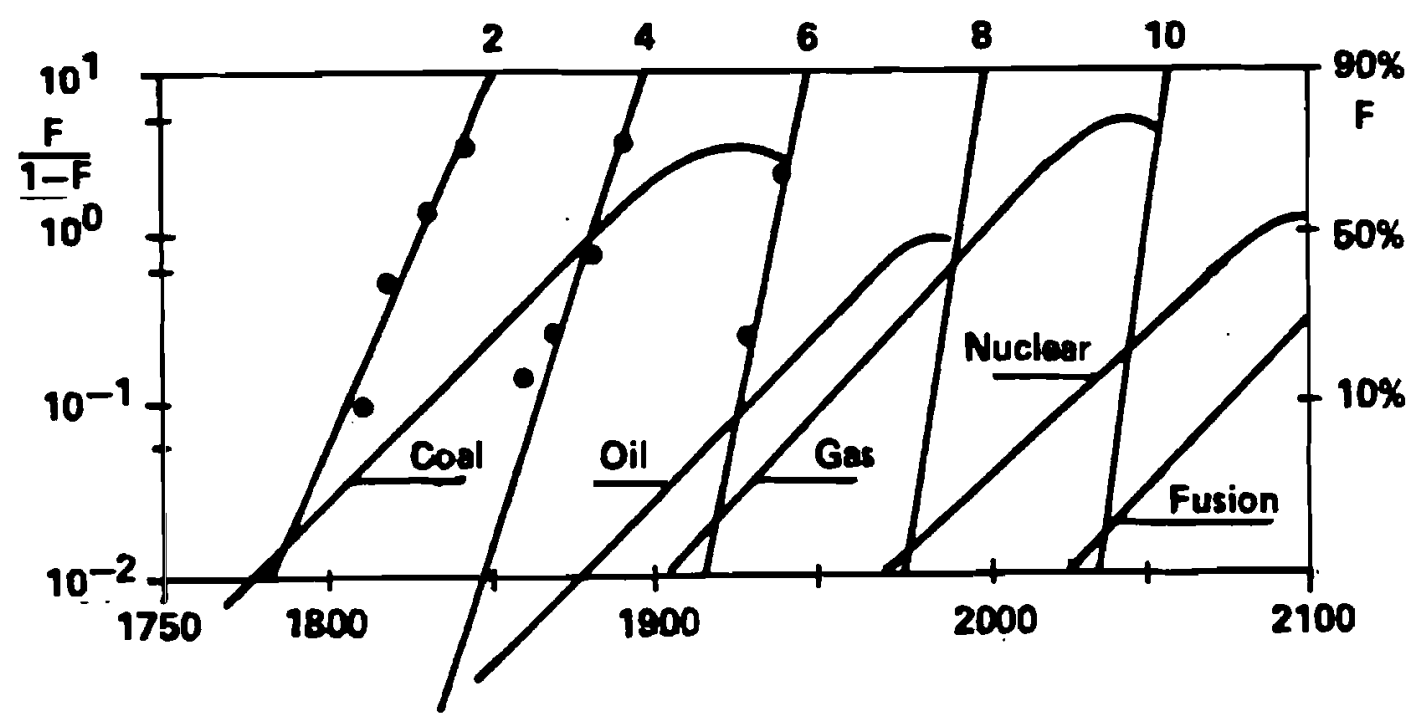

Fig.6. This chart reports innovation waves, marked with a number and segments of the primary energy waves of Fig.5, in order to show their synchronization. The innovation lines show the number of innovations already commercialized at a certain date, expressed as a fraction of the total number of innovation appearing in that wave. 